\title{
Addressing crop interactions within cropping systems in LCA
}

Pietro Goglio ${ }^{\mathrm{a}}$, Gerhard Brankatschk ${ }^{\mathrm{b}}$, Marie Trydeman Knudsen ${ }^{\mathrm{c}}$, Adrian G Williams ${ }^{\mathrm{a}}$, Thomas Nemecek ${ }^{\mathrm{d}}$

${ }^{a}$ School of Water, Energy and Environment, Cranfield University, Cranfield, Bedford, MK43 OAL, UK

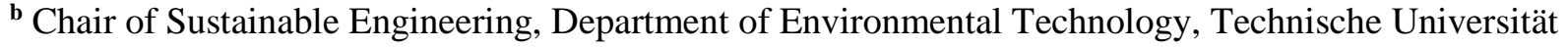

Berlin, Strasse des 17. Juni 135, 10623 Berlin, Germany

${ }^{\mathrm{c}}$ Department of Agroecology - Agricultural Systems and Sustainability, Aarhus University, Blichers Allé 20, 8830 Tjele, Denmark

${ }^{\mathrm{d}}$ Agroscope, Research Department Agroecology and Environment, LCA research group, Reckenholzstrasse 191, CH-8046 Zürich, Switzerland

*Corresponding author.

Pietro Goglio $\mathrm{PhD}$

School of Water, Energy and Environment

Cranfield University, Cranfield, Bedfordshire MK43 0AL

Tel: +44 (0) 1234750111 (extension 4293)

Mail:pietro.goglio@gmail.com 


\begin{abstract}
Purpose

The focus of the Life Cycle Assessment (LCA) of an agricultural plant product is typically on one crop. However, isolating one crop from the cropping system that it belongs to is often challenging because the crops are often interlinked with the other crops in the cropping system. The main objectives of this discussion article are: i) to discuss the characteristics of cropping systems which might affect the LCA methodology, ii) to discuss the advantages and the disadvantages of the current available methods for the life cycle assessment of cropping systems and iii) to offer a framework to carry out LCA of crops and cropping systems.
\end{abstract}

\title{
Methods
}

The definition of cropping systems is provided together with a description of two types of LCA: product LCA and system LCA. The LCA issues related to cropping systems characteristics have been classified as 1) crop interrelationship, 2) crop management and emissions, and 3) functional unit issues. The LCA approaches presented are: Cropping System, Allocation approaches, Crop-by-Crop approach, Combined approaches. The various approaches are described together with their advantages and disadvantages, applicability, comprehensiveness and accuracy.

\section{Results and discussion}

The Cropping System approach is best suited for system LCA. For product LCA, none of the methods is fully exhaustive and accurate. The crop sequence approach takes into consideration cropping systems issues if they happen within the year or season and cannot be applied for intercropping and agroforestry systems. The allocation approaches take into consideration cropping system effects by establishing a mathematical relationship between crops present in the cropping systems. The Model for integrative Life Cycle Assessment in Agriculture (MiLA) approach considers cropping systems issues if they are related to multiproduct and nutrient cycling; while the Crop-by-Crop approach is highly affected by assumptions and considers cropping system issues only if they are related to the analysed crop.

\section{Conclusions}

Each LCA approach presents advantages and disadvantages. For system LCA, the Cropping Systems approach is recommended. For product LCA, environmental burdens should be attributed applying the following hierarchy: 1) attributed to the crop if based on a clear causality; 2) attributed with combined approaches and specific criteria; 3 ) attributed with allocation approaches and generic criteria. These approaches should be combined with the Cropping System approach.

\section{Keywords:}

LCA, methods, allocation, cropping systems, crop, cropping system characteristics, product LCA, system LCA 


\section{Introduction}

Life cycle assessment (LCA) methodology is being increasingly applied and developed across all economic sectors and is widely used for estimating environmental impacts (Klöpffer and Curran 2014). In agriculture, it has been widely adopted for the assessment and comparison of production chains due to its ability to identify environmental hotspots (Gasol et al. 2012; Miller et al. 2006). LCA is also a useful tool to assess environmental trade-offs among different sources of pollution (Brandão et al. 2011; Kulak et al. 2013; Ridoutt et al. 2011).

Including all the environmental impacts and emissions in agricultural LCAs of crops is, however, challenged by the fact that crops are often interlinked with the other crops in the cropping system. The typical application of LCA is to focus on one product, i.e. one crop. However, isolating one crop and its emissions from the cropping system that it is part of is often challenging or maybe even impossible. The effect of cropping systems on single crops has been widely discussed (Brankatschk and Finkbeiner 2015; Hokazono and Hayashi 2015; Peter et al. 2017), including the benefits of cropping systems on agronomic and economic performance, soil fertility and environmental pollution (Brady and Weil 2002; Goglio et al. 2012; Hokazono and Hayashi 2015). In cropping systems, it has been observed that the performance of a crop is often significantly affected by the previous crop in the cropping system (Hokazono and Hayashi 2015; Knudsen et al. 2014; Nemecek et al. 2015; Peter et al. 2017). Several effects of crop management can have long term consequences on soil organic matter, nitrogen availability, weed population, biodiversity (Brady and Weil 2002; Goglio et al. 2015; Knudsen et al. 2017). Most of these effects are dynamic, scale-dependent, nonlinear and hard to quantify within LCA (Curran et al. 2011; Knudsen et al. 2017; Peter et al. 2017) and insufficiently considered in LCA of cropping systems (Peter et al. 2017).

Furthermore, several studies highlight the difficulty in assessing the intrinsic environmental variability of cropping systems which are highly dependent on the interaction between soil, climate conditions and crop management (Gabrielle and Gagnaire 2008; Goglio et al. 2014; Kim et al. 2009; Mazzoncini et al. 2008; Peter et al. 2017). This causes relevant issues with standard concepts commonly adopted and used in LCA such as spatial and temporal boundary (ISO 2006a, 2006b, 2013, 2014). Cropping systems also produce several products. This issue makes the identification of the functional unit challenging and constitutes an important scientific debate (Goglio et al. 2014; Hayashi 2013; Nemecek et al. 2011a, 2011b; Peter et al. 2017).

To better capture crops and cropping systems, several allocation approaches have been developed to fully assess cropping systems (Brankatschk and Finkbeiner 2014, 2015). One approach is based on the agriculturespecific biophysical Cereal Unit, developed for the purpose of agricultural statistics, while the other on a common agricultural denominator criterion (e.g. energy content, mass basis) for allocation (Brankatschk and Finkbeiner 2014, 2015). The Model for integrative Life Cycle Assessment in Agriculture (MiLA) tool has also been proposed to better consider crop rotations with energy crops (Peter et al. 2017). In addition, Knudsen et al. (2014) and Nemecek et al. (2015) have proposed a dual approach which takes either each 
crop/crop combination separately or the cropping system as a whole into account. However, despite the fact that issues related to the assessment of cropping systems in LCA are widely recognised (Goglio et al. 2012, 2014; Knudsen et al. 2014; Nemecek et al. 2011a, 2011b), no consensus has been found on how to assess cropping systems within the LCA framework (Peter et al. 2017).

The main objectives of this discussion article are: i) to discuss the characteristics of cropping systems which might affect the LCA methodology, ii) to discuss the advantages and the disadvantages of the current available methods for the life cycle assessment of cropping systems and iii) to offer a framework to carry out LCA of crops and cropping systems.

\section{Definitions and concepts}

As observed by Malézieux (2012), cropping systems can have variable composition, a different level of complexity and are generally composed by a series of crops. Thus, for the purpose of this article, a cropping system correspond to a piece of land where one or a series of crops are grown either following each other (temporal perspective, for instance in rotations, but also crop monoculture) or sharing the same field (space perspective: intercropping and agroforestry), considered with a systematic approach. In this article, the discussion is limited to cropping systems with field and tree crops, not to pastures or systems including livestock grazing.

Different types of LCA can be considered on the basis of the purpose of LCA. Product LCA is a life cycle assessment which has the purpose of assessing the environmental profile of a product produced by a cropping systems. For instance, Brentrup et al. (2004) and Charles et al. (2006) carried out a LCA of wheat (Triticum aestivum L.) production, while Williams et al. (2010) carried out LCA of wheat together with oilseed rape (Brassica napus L.) and potatoes (Solanum tuberosum L.). This type of LCA was previously referred to as product-oriented by Hayashi (2013). A particular type of product LCA is the inventory LCA which is focused on developing the inventory for a particular system, product and service to be stored in an LCI database and made available for general use by LCA practitioners. Generally, they are carried out following a framework which is specific to the Life Cycle Inventory. For instance, Nemecek et al. (2014) proposed a set of guidelines which are applicable for a system or product in the World Food Life Cycle Database (www.quantis-intl.com/wfldb).

In contrast with product LCA, in system LCA the focus and the purpose of the LCA is to assess and compare production systems (e.g. cropping systems) using LCA to have a better understanding of the environmental mechanisms responsible for environmental impacts. System LCA were also called land-oriented LCA by Hayashi (2013). Some examples of this type of LCA are Nemecek et al. (2011a, 2011b) where different cropping systems in Swiss conditions have been tested (organic and integrated, intensive and extensive). Other examples for North American conditions are the following: Goglio et al. (2014); Kim et al. (2009); MacWilliam et al. (2014). System LCA are often used for site-specific assessment. 
Cropping systems have a series of characteristics which makes them particularly challenging to assess within LCA. A common characteristic of cropping systems is that they have a large variability which is due to the combined effect of soil and climate characteristics (Börjesson and Tufvesson 2011; Goglio et al. 2014; Peter et al. 2017; Petersen et al. 2011). These characteristics can be grouped in crop interrelationship characteristics, crop management and emission characteristics and functional unit characteristics.

\subsection{Characteristics related to crop interrelationships}

Crops in cropping systems are closely related. For instance, in the LCA of intercropping and agroforestry systems where more than one crop share the same space but might have a different crop management, the distinction between each crop present in the cropping system is often fuzzy. Thus, careful description of the system boundary is necessary, in agreement with the ISO standards (ISO 2006a, 2006a, 2013). Similar spatial issues in LCA of cropping systems can be found when assessing the impacts of crop management with regard to biodiversity (Knudsen et al. 2017). Indeed biodiversity is affected by both the management carried out in the field and landscape variability (Gabriel et al. 2010; Zimmerer et al. 2015). Thus, from a LCA perspective, it is particularly challenging to attribute the impact on biodiversity due to a particular crop or crop management present in one field independently from the surrounding (Curran et al. 2016; Knudsen et al. 2017).

The cropping systems and crop assessment are also particularly complex with regard to nutrient dynamics which affect the yield and environmental performance. In particular, nutrient availability is not constant and can be affected by previous crops, crop management and soil characteristics (Goglio et al. 2014; Hokazono and Hayashi 2015; Kulak et al. 2013; Mazzoncini et al. 2008; Nemecek et al. 2015). For instance, N availability is affected by residue, manure and fertiliser application, soil cultivation and the system involved may occur within the same season or in the following seasons, thus affecting the performance of the following crops (Brady and Weil 2002; Peter et al. 2017). Catch crops are also often part of the nutrient management of a cropping system and the benefits and burdens of those should be attributed to the crops in the cropping system.

Residue management is particularly important for outbreaks of pathogens in the following years, as it can happen for rust in wheat or for potato blight in potato (Soffe 2003). Further, weed populations are largely affected by the history of previous crop management practices as shown by Shea et al. (2010). On the other hand, crop cover and residue availability largely affect soil erosion (Brady and Weil 2002).

\subsection{Crop management and environmental emissions and impacts}

Different from many industrial systems, cropping systems have a variable crop management that mostly depends on soil, climate conditions and crop characteristics (Peter et al. 2017; Soffe 2003). Together with these aspects, the presence of weeds and pathogens largely affect the overall yield of the crop but also its environmental performance (Brankatschk and Finkbeiner 2015; Goglio et al. 2012; Kulak et al. 2013; Nemecek et al. 2015). Thus, from a LCA perspective, the same crop or agricultural product can have large 
differences in the values for each impact category depending on the interaction of crop management with climate and soil (Peter et al. 2017).

Several environmental impacts related to cropping systems such as soil $\mathrm{CO}_{2}$ emissions, $\mathrm{N}$ leaching, $\mathrm{N}_{2} \mathrm{O}$ emissions, and effects of pathogens or weeds affecting pesticide use are also observed in the following years when other crops are grown (Brady and Weil 2002; Goglio et al. 2015). For instance, part of the N leaching and $\mathrm{N}_{2} \mathrm{O}$ emissions from ploughing in a clover (Trifolium $s p$ ) field will occur in the following crop. $\mathrm{N}_{2} \mathrm{O}$ emissions depends on a large number of factors including moisture, nitrogen availability in the soil, residue management and soil characteristics (Saggar 2010). These latter factors have dynamics, which can affect the following crops. From an LCA perspective, the time scale of $\mathrm{N}_{2} \mathrm{O}$ emissions and their drivers are key issues when carrying out an LCA of a cropping system, considering that recent research suggests that direct $\mathrm{N}_{2} \mathrm{O}$ emissions can contribute up to $70 \%$ of the total Global Warming Potential (GWP) for the agricultural phase (Goglio et al. 2014; Zaher et al. 2013). Likewise for soil $\mathrm{CO}_{2}$ emissions, which are a key aspect with regard to LCA of cropping systems considering the soil C sequestration potential (Petersen et al. 2013). Indeed, soil C dynamics can be slow (Brady and Weil 2002; Paustian et al. 2016) even up to 100 years later in some cold climates (Börjesson and Tufvesson 2011; Goglio et al. 2015; Petersen et al. 2011; Tuomisto et al. 2015). Thus, from a LCA perspective, the attribution of soil $\mathrm{CO}_{2}$ emissions, $\mathrm{N}_{2} \mathrm{O}$ emissions and $\mathrm{N}$ leaching to a given crop is particularly challenging. Another challenge is accounting for water footprint in agroforestry or intercropping systems, because the crops share the same water resources.

In a similar manner, soil erosion and soil P loss are other potential impacts, which should be accounted for when carrying out an LCA of cropping systems, but there is no consensus on how to account for these impacts with regard to the different types of LCA. Some research proposes an integrated approach which consider soil erosion and soil P loss as related systems (Nemecek et al. 2014). Further, both processes have spatial effects and the potential that the actual impact will occur is variable depending on rainfall, soil characteristics, and soil cover which have a temporal dynamics (Brady and Weil 2002).

\subsection{Functional unit (FU) characteristics}

Different from industrial systems, cropping systems cause issues in identifying functional unit. Several authors highlight that agricultural systems have several functions at the same time (Goglio et al. 2014; Hayashi 2013; Nemecek et al. 2011a). Especially for product LCA, the choice of functional unit is particularly critical as different products are produced at the same time. For instance, in cropping systems where food crops are cultivated with fodder, energy or fibre crops, the choice of a representative functional unit for productivity is difficult. Particularly challenging is also the identification of a functional unit in agroforestry or intercropping systems. 


\section{Methodological approach for system LCA: the Cropping System approach}

The Cropping System approach has been applied in several system LCAs for cropping systems in Europe and North America (Dendooven et al. 2012; Goglio et al. 2012, 2014; Knudsen et al. 2014; Nemecek et al. 2011b, 2011a, 2015; Williams et al. 2010). For instance, the Cropping System approach has been adopted to compare organic vs. integrated cropping systems with wheat, maize (Zea mays L.), barley (Hordeum vulgare L.), beetroot (Beta vulgaris L.), potato and clover grass ley in Swiss conditions (Nemecek et al. 2011a). In this approach, the cropping system is considered as a whole system producing different products (Fig. 1). With the Cropping System approach, when considering as functional unit either t of yield, cereal units, GJ of energy output or agricultural income output in currency unit (i.e. \$/£/€/CHF), the value obtained for the whole system gives an estimate of the overall environmental impacts of the system.

This approach takes into consideration the processes involved within a cropping system especially from a temporal perspective. With the cropping system approach, the interaction of crop management with soil and climate conditions is fully taken into account. This approach allows to carry out site-specific assessment LCA using emission measurements and model simulation (Dendooven et al. 2012; Goglio et al. 2014; Zaher et al. 2013). Finally, the cropping system approach better assesses complex systems such as agroforestry and intercropping systems. Thus, this approach is well suited for system LCA. However, it does not provide results for individual crops and products; for this purpose, the methods described in the next section can be used.

\section{Methodological approaches for product LCA}

For product LCA (Fig. 2), it is particularly challenging to properly account for different cropping systems effects. Table 1 shows issues which can be mainly attributed to a crop and others which require specific or generic attribution criteria. As Table 1 shows, some characteristics related to cropping systems can be mainly attributed to each single crop. The classification is based on the causal relationships between management interventions, resource use or emissions and the cultivation of the different crops. For instance, all the cropping systems issues strictly related to crop management or pollution effects which occurs within the season can be easily attributed to a crop (Fig. 2), like sowing maize (including machinery operations and the seed), which is clearly motivated only by maize cultivation. In contrast, application of lime or installation of drainage cannot be linked to a single crop. Many aspects related to cropping systems require a criterion to be attributed to a crop. As shown in Table 1 and figure 2 different criteria could be used to attribute characteristics to a crop in a cropping system, depending on data availability, user expertise and complexity of the cropping system to be analysed.

A comparison among the various approaches is presented in Table 2. Several criteria have been adopted: applicability, comprehensiveness and accuracy. A medium level of applicability has been attributed to the approaches which require the knowledge of the crop sequence to be adopted, instead a high level of applicability was attributed when the approach can be used independently from the crop sequence. A high level of comprehensiveness was attributed when the approach considers most of cropping systems issues; a 
medium level of comprehensiveness was attributed to the approaches adopting a criterion which only partially reflects the dynamics of cropping system issues, but still considering them. Finally, a low level of comprehensiveness was attributed to the approach that fully disregards cropping system issues. Instead a high level of accuracy had been attributed to approaches which largely reflect the cause-effect relationships between cropping system characteristics, a medium level to approaches which partially incorporate the relationships between cropping system characteristics; finally a low level of accuracy is attributed to approaches which fully disregard causal relationships within cropping system characteristics.

\subsection{Allocation approaches: crop rotation and cereal unit}

Allocation approaches are based on allocating the environmental burdens to a crop on the basis of a generic criterion (Table 1, Fig. 2). These approaches maintain the integrity of the cropping systems and can be as well used for agroforestry and intercropping (Table 2). However as stated in the ISO standards, allocation approaches should be avoided when possible (ISO 2006a, 2006b), such in the case of specific crop management intervention easily attributable to a crop (e.g., seeding). In the case of Cereal Unit allocation, the allocation is based on the biophysical Cereal Unit (CU), developed by German agricultural authorities and scientists and regularly updated and continuously used in German agricultural statistics. Accordingly, the yields of various agricultural products are expressed in Cereal Unit equivalents. For this purpose, a number of $\mathrm{CU}$ conversion factors exist for vegetable products, animal products, co-products, and products from primary processing. To calculate $\mathrm{CU}$ conversion factors, the metabolizable energy content of each agricultural product is determined and normalized using barley as a reference. Further details are explained in Brankatschk and Finkbeiner (2014) where this approach has been described and tested for wheat, barley, soybean (Glycine max (L.) Merr.), oilseed rape, sugarbeet (Beta vulgaris L.) and sunflower (Helianthus annuus L.). Since 2014, the cereal unit has been used in agricultural LCAs to allocate impacts to crop products (Brankatschk and Finkbeiner 2014). It has the main advantage of keeping cropping system integrity while at the same time it can be used for product LCA.

Cereal Unit allocation presents a series of disadvantages. For instance, cereal units are focused on feed and food crops. Further, the allocation of the impacts does not reflect the time dynamics of cropping systems, despite considering it. Cereal units can only be applied in German conditions, however as highlighted by Brankatschk and Finkbeiner (2014), several countries and worldwide institutions (e.g. Food and Agriculture Organization of the United Nations (FAO)) have developed similar metrics which could be used for cropping systems containing food and feed crops.

The Crop Rotation approach, also proposed by Brankatschk and Finkbeiner (2015) can be distinguished from the cereal unit because in this case the environmental burden is allocated in the life cycle inventory amongst all crop rotation elements using e.g. biophysical, cereal unit, mass basis, energy or economic basis (Brankatschk and Finkbeiner 2015). This approach has been tested in a crop rotation containing sugar beet, spring barley, winter wheat, rapeseed, winter wheat in German conditions and applying the cereal unit criterion (Brankatschk and Finkbeiner 2015). This approach does not affect other phases of LCA. As 
consequence, the functional unit remains unchanged and the approach is suitable to product LCAs (Brankatschk and Finkbeiner 2015). However as the Cereal Unit approach, also the Crop Rotation approach only partially reflect the cause-effect relationship among cropping systems characteristics and requires additional information regarding the crop rotation to be adopted (Table 2).

\subsection{Crop-by-Crop approach}

The Crop-by-Crop approach considers each crop as a separate entity from the previous and following crops (Fig. 1, 2). This approach is the most commonly adopted for product LCA. It has been adopted for several LCAs including food and non-food crops (Brentrup et al. 2004; Charles et al. 2006; Goglio and Owende 2009; Ingrao et al. 2015; Iriarte et al. 2010). For instance, Brentrup et al. (2004) and Charles et al. (2006) applied this approach to assess wheat with different level of $\mathrm{N}$ fertiliser application in UK and Swiss conditions. The main advantage of this approach is its applicability for product LCA. Indeed this approach does not requires a high level of agricultural expertise, since only data on the respective crop have to be collected (Table 2). Further no particular knowledge of cropping systems is required. However, this approach considers temporal effects of crop management only if they occur during the considered crop season making it inaccurate (Table 2).

\subsection{Combined approaches}

The Crop Sequence approach is a combined approach developed by Nemecek et al. (2015) to include cropping system effects for 64 rotations across France. Together with the crop, the preceding crop is considered as part of a crop combination. For instance, winter wheat is assessed as following cereals, pea (Pisum sativum L.), oilseed rape or sunflower (Helianthus annuus L.) (Fig. 1, 2). Furthermore, each single crop combination is also distinguished for the presence or absence of catch crops. It presents the advantage of capturing and reflecting the cause-effect relationship of the cropping system characteristics, but it requires expertise, data and time to be adopted (Nemecek et al. 2015) (Table 2).

The "Model for integrative Life Cycle Assessment in Agriculture" (MiLA) was conceived to assess GHG emissions and cumulative energy demand CED of agricultural cropping systems including energy crops. It has been tested to assess biogas production systems in German conditions. The crop rotations included barley, maize, hybrid sudangrass (Sorghum bicolor $\times$ Sorghum sudanense), triticale ( $\times$ Triticosecale (Camus) Wittm.), phacelia (phacelia tanacetifolia Benth.), grass and alfalfa/lucerne (Medicago sativa L.). With regard to crop rotations, the MiLA tool adopts a double approach. It considers nutrient cycling carryover effects and assesses different products out of the systems by adopting different functional units (Peter et al. 2017). In this approach, impacts of crop management and related soil emissions are divided according to the specified number of crops, including the crop where the crop management practice was carried out. For cover crops, environmental burdens from the entire cultivation process are divided according to the number of crops that benefit from the nutrients supplied. 
The MiLA Tool presents the advantages of including cropping systems and some crop management effects by including the entire crop rotation in the assessment (Table 2). Intermediate results allow practitioners to use their own allocation approaches. Thus, this approach is theoretically suitable for product LCA. However, it excludes other issues such as soil organic carbon effects, impacts of biodiversity which have been considered very important within the LCA community (Goglio et al. 2014, 2015; Knudsen et al. 2017; Petersen et al. 2013). A similar approach was also used in Knudsen et al. (2014).

The Crop Sequence approach and partially the MiLA approach present a series of advantages: they fix a temporal limit between different crops and allow the user to consider potential cropping system effects if they occur in the short term (Table 2). However, they present the disadvantages of not including long term crop management and crop effects. Further, they cannot be applied for intercropping and agroforestry systems. They also require more data and expertise on the cropping system and more time to be adopted (Nemecek et al. 2015; Peter et al. 2017).

\subsection{Discussion}

The approaches for product LCA hold some advantages and disadvantages for each approach (Table 2). The Crop Sequence approach can include cropping system effects occurring in the short term but excludes cropping systems effects in the long term outside the crop seasons or year and cannot be adopted in the case of intercropping or agroforestry systems (Nemecek et al. 2015). The allocation approaches attribute the environmental burden on the basis of an a priori criteria that is associated with the cropping systems but it does not reflect it (Brankatschk and Finkbeiner 2014, 2015).

The Crop-by-Crop approach presents several limitations. For instance, time variability is considered only if it occurs during the analysed crop seasons. With the Crop-by-Crop approach, there is a high risk of double counting for GHG, nutrient dynamics and biodiversity impact. The allocation approach using the Cereal Unit cannot be applied fully to agroforestry systems without conversion factors, for crops without conversion factors and for countries other than Germany. However similar frameworks are applicable worldwide (Table

2) (Brankatschk and Finkbeiner 2014). Further, allocation approaches and MiLA approach are also more complex than the Crop-by-Crop approach, but simpler than the Crop Sequence approach (Table 2). Due to the crop interrelationship and the limitations of product LCA approaches currently available, a dual approach should be adopted involving the Cropping System approach and a specific approach for product LCA (i.e. Allocation, MiLA approach, Crop-by-Crop, Crop Sequence) as it has been suggested and carried out by several authors (Knudsen et al. 2017; Nemecek et al. 2015).

\section{Recommendations:}

On the basis of the present discussion the following recommendations can be drawn:

- The approach adopted should be consistent with the objectives of the LCA study (ISO 2006a, 2006b) 
- Issues related to the approach adopted should be discussed by the LCA practitioner, in agreement with the ISO standard (ISO 2006a, 2006b)

- For system LCA, the Cropping System approach is recommended. It can be combined with one of the other approaches in order to disaggregate crop rotation impacts to single crops.

- For product LCA:

1. The environmental burden of cropping systems issues easily related to the crop should be fully attributed to the corresponding crops (Table 1). For instance, for a crop management practice (seeding), the emissions of machinery should be attributed to the corresponding crop when the crop management practice occurs.

2. For the environmental burden of cropping systems issues (Table 1) which need to attributed to a crop, combined approaches using specific attribution criteria should be adopted where possible. For instance, this approach could be used when assessing soil P loss with regard to eutrophication potential for cropping system containing wheat, clover and potatoes.

3. If specific criteria cannot be established and a combined approach adopted, allocation approaches with generic attribution criteria should be applied.

Where possible a dual approach should be adopted (cropping system approach with one of the approaches specific for product LCA).

The choice among different methods should also consider data availability and user expertise as proposed by Goglio et al. (2015) for soil C. However, the level of complexity among the various approaches is relatively limited. Considering the Potting and Hauschild (2006)'s classification, all approaches allow to carry out a site-specific, site-dependent and site-generic LCA assessment.

Further research in comparing different approaches is necessary to estimate their potential uncertainties. Some research already evaluated the outcomes of adopting the MiLA approach with the Crop-by-Crop approach and reported a difference of up 99\% for global warming potential per ha (Peter et al. 2017). Considering the increasing importance of LCA of crops and cropping systems and in view of increasing accuracy in the assessment, the rotation and cropping system effects on crop performance cannot be neglected.

\section{Conclusions}

The main aim of this article was to discuss the different approaches currently available to carry out LCA of cropping systems. In the case of system LCA, the Cropping System approach should be adopted. For product LCAs, none of the currently available approaches is exhaustive but each of them present advantages and disadvantages which should be considered and discussed by the LCA practitioner while carrying out an LCA of cropping systems. For product LCA, environmental burdens should be attributed applying the following hierarchy: 1) attributed to the crop if based on a clear causality; 2) attributed with combined approaches and 
specific criteria; 3) attributed with allocation approaches and generic criteria. These approaches should be combined with the Cropping System approach. The adoption of these recommendations is subject to user expertise, data and time availability. Instead, for system LCA, the approaches available should be adopted in combination with the Cropping System approach. Future research should focus on developing other approaches to fully encompass cropping systems characteristics in the LCA of cropping systems and carrying out a quantitative assessment of the approaches currently available.

\section{References}

Börjesson P, Tufvesson LM (2011). Agricultural crop-based biofuels - resource efficiency and environmental performance including direct land use changes. J Clean Prod 19:108-120. doi: 10.1016/j.jclepro.2010.01.001

Brady N, Weil R (2002). The Nature and Properties of Soils, 13th ed. Prentice Hall, Upper Saddle River, New Jersey, USA

Brandão M, Milà i Canals L, Clift R (2011). Soil organic carbon changes in the cultivation of energy crops: Implications for GHG balances and soil quality for use in LCA. Biomass Bioenerg 35:2323-2336. doi: 10.1016/j.biombioe.2009.10.019

Brankatschk G, Finkbeiner M (2014). Application of the Cereal Unit in a new allocation procedure for agricultural life cycle assessments. J Clean Prod 73:72-79. doi: 10.1016/j.jclepro.2014.02.005

Brankatschk G, Finkbeiner M (2015). Modeling crop rotation in agricultural LCAs — Challenges and potential solutions. Agr Syst 138:66-76. doi: 10.1016/j.agsy.2015.05.008

Brentrup F, Küsters J, Kuhlmann H, Lammel J (2004). Environmental impact assessment of agricultural production systems using the life cycle assessment methodology.I. Theoretical concept of a LCA method tailored to crop production. Eur J Agr 20:247-264. doi: 10.1016/S1161-0301(03)00024-8

Charles R, Jolliet O, Gaillard G, Pellet D (2006). Environmental analysis of intensity level in wheat crop production using life cycle assessment. Agric Ecosys Environ 113:216-225. doi: 10.1016/j.agee.2005.09.014

Curran M, de Baan L, De Schryver AM, van Zelm R, Hellweg S, Koellner T, Sonnemann G, Huijbregts MAJ (2011). Toward Meaningful End Points of Biodiversity in Life Cycle Assessment. Environ Sci Technol 45:70-79. doi: 10.1021/es101444k

Curran M, Maia de Souza D, Antón A, Teixeira RFM, Michelsen O, Vidal-Legaz B, Sala S, Milà i Canals L (2016). How Well Does LCA Model Land Use Impacts on Biodiversity? - A Comparison with Approaches from Ecology and Conservation. Environ Sci Technol 50:2782-2795. doi: 10.1021/acs.est.5b04681

Dendooven L, Patino-Zuniga L, Verhulst N, Luna-Guido M, Marsch R, Govaerts B (2012). Global warming potential of agricultural systems with contrasting tillage and residue management in the central highlands of Mexico. Agric Ecosys Environ 152 doi: 10.1016/j.agee.2012.02.010

Gabriel D, Sait SM, Hodgson JA, Schmutz U, Kunin WE, Benton TG (2010). Scale matters: the impact of organic farming on biodiversity at different spatial scales. Ecol Lett 13:858-869. doi: 10.1111/j.1461-0248.2010.01481.x

Gabrielle B, Gagnaire N (2008). Life-cycle assessment of straw use in bio-ethanol production: A case study based on biophysical modelling. Biomass Bioenerg 32:431-441. doi:

10.1016/j.biombioe.2007.10.017 
Gasol CM, Salvia J, Serra J, Antón A, Sevigne E, Rieradevall J, Gabarrell X (2012). A life cycle assessment of biodiesel production from winter rape grown in Southern Europe. Biomass Bioenerg 40:71-81. doi: 10.1016/j.biombioe.2012.02.003

Goglio P, Owende PMO (2009). A screening LCA of short rotation coppice willow (Salix sp.) feedstock production system for small-scale electricity generation. Biosyst Eng 103:389-394. doi: 10.1016/j.biosystemseng.2009.03.003

Goglio P, Bonari E, Mazzoncini M (2012). LCA of cropping systems with different external input levels for energetic purposes. Biomass Bioenerg 42:33-42. doi: 10.1016/j.biombioe.2012.03.021

Goglio P, Grant BB, Smith WN, Desjardins RL, Worth DE, Zentner R, Malhi SS (2014). Impact of management strategies on the global warming potential at the cropping system level. Sci Tot Environ 490:921-933. doi: 10.1016/j.scitotenv.2014.05.070

Goglio P, Smith WN, Grant BB, Desjardins RL, McConkey BG, Campbell CA, Nemecek T (2015). Accounting for soil carbon changes in agricultural life cycle assessment (LCA): a review. J Clean Prod 104:23-39. doi: 10.1016/j.jclepro.2015.05.040

Hayashi K (2013). Practical recommendations for supporting agricultural decisions through life cycle assessment based on two alternative views of crop production: the example of organic conversion. Int J Life Cycle Assess 18:331-339. doi: 10.1007/s11367-012-0493-9

Hokazono S, Hayashi K (2015). Life cycle assessment of organic paddy rotation systems using land- and product-based indicators: a case study in Japan. Int J Life Cycle Assess 20:1061-1075. doi: 10.1007/s11367-015-0906-7

Ingrao C, Matarazzo A, Tricase C, Clasadonte MT, Huisingh D (2015). Life Cycle Assessment for highlighting environmental hotspots in Sicilian peach production systems. J Clean Prod 92:109-120. doi: $10.1016 /$ j.jclepro.2014.12.053

Iriarte A, Rieradevall J, Gabarrell X (2010). Life cycle assessment of sunflower and rapeseed as energy crops under Chilean conditions. J Clean Prod 18:336-345. doi: 10.1016/j.jclepro.2009.11.004

ISO (2006)(a). SS-EN ISO 14040 Environmental Management- Life Cycle Assessment, Principles and Framework. International Organization for Standardization, Geneva

ISO (2006)(b). SS-EN ISO 14044 Environmental Management - Life Cycle Assessment - Requirements and Guidelines. International Organization for Standardization, Geneva

ISO (2013). TS-EN ISO 14067 Greenhouse Gases -Carbon Footprint of Products- Requirements and Guidelines for Quantification and Communication. International Organization for Standardization, Geneva

ISO (2014). BS-EN ISO 14046 Environmental management — Water footprint — Principles, requirements and guidelines. International Organization for Standardization, Geneva

Kim S, Dale BE, Jenkins R (2009). Life cycle assessment of corn grain and corn stover in the United States. Int J Life Cycle Assess 14:160-174. doi: 10.1007/s11367-008-0054-4

Klöpffer W, Curran M (2014). Background and Future Prospects in Life Cycle Assessment. Series: LCA compendium - The complete World of Life Cycle assessment., Springer. ed. Dordrecht, the Netherlands

Knudsen MT, Meyer-Aurich A, Olesen JE, Chirinda N, Hermansen JE (2014). Carbon footprints of crops from organic and conventional arable crop rotations - Using a life cycle assessment approach. $\mathrm{J}$ Clean Prod 64:609-618. doi: 10.1016/j.jclepro.2013.07.009 
Knudsen MT, Hermansen JE, Cederberg C, Herzog F, Vale J, Jeanneret P, Sarthou J-P, Friedel JK, Balázs K, Fjellstad W, Kainz M, Wolfrum S, Dennis P (2017). Characterization factors for land use impacts on biodiversity in life cycle assessment based on direct measures of plant species richness in European farmland in the 'Temperate Broadleaf and Mixed Forest' biome. Sci Tot Environ 580:358-366. doi: 10.1016/j.scitotenv.2016.11.172

Kulak M, Nemecek T, Frossard E, Gaillard G (2013). How Eco-Efficient Are Low-Input Cropping Systems in Western Europe, and What Can Be Done to Improve Their Eco-Efficiency? Sustainability 5:3722-3743. doi: 10.3390/su5093722

MacWilliam S, Wismer M, Kulshreshtha S (2014). Life cycle and economic assessment of Western Canadian pulse systems: The inclusion of pulses in crop rotations. Agric Syst 123:43-53. doi: 10.1016/j.agsy.2013.08.009

Malézieux E (2012). Designing cropping systems from nature. Agron Sustain Dev 32:15-29. doi: $10.1007 / \mathrm{s} 13593-011-0027-\mathrm{z}$

Mazzoncini M, Di Bene C, Coli A, Antichi D, Petri M, Bonari E (2008). Rainfed Wheat and Soybean Productivity in a Long-Term Tillage Experiment in Central Italy. Agron J 100:1418-1429. doi: 10.2134/agronj2007.0173

Miller SA, Landis AE, Theis TL (2006). Use of Monte Carlo analysis to characterize nitrogen fluxes in agroecosystems. Environ Sci Technol 40:2324-2332. doi: 10.1021/es0518878

Nemecek T, Dubois D, Huguenin-Elie O, Gaillard G (2011)(a). Life cycle assessment of Swiss farming systems: I. Integrated and organic farming. Agr Syst 104:217-232. doi: 10.1016/j.agsy.2010.10.002

Nemecek T, Huguenin-Elie O, Dubois D, Gaillard G, Schaller B, Chervet A (2011)(b). Life cycle assessment of Swiss farming systems: II. Extensive and intensive production. Agr Syst 104:233-245. doi: 10.1016/j.agsy.2010.07.007

Nemecek T, Bengoa X, Lansche J, Mouron P, Rossi V, Humbert S (2014). Methodological Guidelines for the Life Cycle Inventory of Agricultural Products. Version 2.0. World Food LCA Database (WFLDB). Quantis and Agroscope, Lausanne and Zurich, Switzerland

Nemecek T, Hayer F, Bonnin E, Carrouée B, Schneider A, Vivier C (2015). Designing eco-efficient crop rotations using life cycle assessment of crop combinations. Eur J Agron 65:40-51. doi: 10.1016/j.eja.2015.01.005

Paustian K, Lehmann J, Ogle S, Reay D, Robertson GP, Smith P (2016). Climate-smart soils. Nature 532:49-57. doi: 10.1038/nature17174

Peter C, Specka X, Aurbacher J, Kornatz P, Herrmann C, Heiermann M, Müller J, Nendel C (2017). The MiLA tool: Modeling greenhouse gas emissions and cumulative energy demand of energy crop cultivation in rotation. Agric Syst 152:67-79. doi: 10.1016/j.agsy.2016.12.008

Petersen BM, Knudsen MT, Hermansen JE, Halberg N (2013). An approach to include soil carbon changes in life cycle assessments. Journal of Cleaner Production 52:217-224. doi:

10.1016/j.jclepro.2013.03.007

Petersen SO, Mutegi JK, Hansen EM, Munkholm LJ (2011). Tillage effects on N2O emissions as influenced by a winter cover crop. Soil Biol Biochem 43:1509-1517. doi: 10.1016/j.soilbio.2011.03.028

Potting J, Hauschild MZ (2006). Spatial differentiation in life cycle impact assessment: A decade of method development to increase the environmental realism of LCIA. Int J Life Cycle Assess 11:11-13. doi: $10.1065 /$ lca2006.04.005 
Ridoutt BG, Sanguansri P, Harper GS (2011). Comparing Carbon and Water Footprints for Beef Cattle Production in Southern Australia. Sustainability 3:2443-2455. doi: 10.3390/su3122443

Saggar S (2010). Estimation of nitrous oxide emission from ecosystems and its mitigation technologies. Agr Ecosyst Environ 136:189-191. doi: 10.1016/j.agee.2010.01.007

Shea K, Jongejans E, Skarpaas O, Kelly D, Sheppard AW (2010). Optimal management strategies to control local population growth or population spread may not be the same. Ecol Applications 20:1148-1161. doi: 10.1890/09-0316.1

Soffe R (2003). 20th Edition Primore McConnell's The Agricultural Notebook. Balckwell Publishing, Oxford, UK; Ames, USA; Victoria, Australia; Berlin, Germany

Tuomisto HL, De Camillis C, Leip A, Nisini L, Pelletier N, Haastrup P (2015). Development and testing of a European Union-wide farm-level carbon calculator. Integr Environ Assess Manag 11:404-416. doi: 10.1002/ieam.1629

Williams AG, Audsley E, Sandars DL (2010). Environmental burdens of producing bread wheat, oilseed rape and potatoes in England and Wales using simulation and system modelling. Int J Life Cycle Assess 15:855-868. doi: 10.1007/s11367-010-0212-3

Zaher U, Stöckle C, Painter K, Higgins S (2013). Life cycle assessment of the potential carbon credit from no- and reduced-tillage winter wheat-based cropping systems in Eastern Washington State. Agric Syst 122:73-78. doi: 10.1016/j.agsy.2013.08.004

Zimmerer KS, Carney JA, Vanek SJ (2015). Sustainable smallholder intensification in global change? Pivotal spatial interactions, gendered livelihoods, and agrobiodiversity. Curr Opin Environ Sustain, Open Issue 14:49-60. doi: 10.1016/j.cosust.2015.03.004

\section{Tables}


Table 1 General guidelines of attribution to a crop for characteristics of cropping system in product LCA

Management interventions, resources and emissions that can be ...

\begin{tabular}{|c|c|c|}
\hline mainly attributed to a single crop ${ }^{a, b}$ & $\begin{array}{l}\text { allocated using specific criteria } \\
\text { (e.g. nutrient uptake/export of a crop, } \\
\text { fertilizer demand of a crop, crop } \\
\text { combination) }^{\text {a,b }}\end{array}$ & $\begin{array}{l}\text { allocated using generic criteria } \\
\text { (e.g. cereal unit, crop rotation) }\end{array}$ \\
\hline $\begin{array}{l}\text { - } \text { Machinery use during crop management } \\
\text { - Pest and pathogen control, if specific to one } \\
\text { crop in the rotation (including machinery use } \\
\text { and pesticide active ingredients) } \\
\text { - Seed input } \\
\text { - Land occupation } \\
\text { - Irrigation } \\
\text { - Soil erosion } \\
\text { b,c }\end{array}$ & $\begin{array}{ll}\text { - } & \text { Fertilisation } \\
\text { - } & \text { Nutrient losses }\left(\mathrm{N} \text {-compounds: } \mathrm{NH}_{3} \text {, }\right. \\
& \mathrm{N}_{2} \mathrm{O}, \mathrm{NO}_{\mathrm{x}}, \mathrm{NO}_{3}, \mathrm{P} \text {-compounds) } \\
\text { - } & \text { Biodiversity }\end{array}$ & $\begin{array}{l}\text { - } \text { Crop management effects on soil (long- } \\
\text { term) } \\
\text { - Weed control (including machinery use } \\
\text { and pesticide active ingredient) } \\
\text { - Pest and pathogen control, if meant to } \\
\text { improve phytosanitary conditions for } \\
\text { more than one crop in the rotation } \\
\text { (including machinery use and pesticide } \\
\text { active ingredient) } \\
\text { - Liming and other soil improvement } \\
\text { measures and related emissions } \\
\text { - Land transformation / land use change } \\
\text { For companion cropping, intercropping } \\
\text { and agroforestry }\end{array}$ \\
\hline
\end{tabular}

${ }^{\text {a }}$ only possible when just one crop at time grows in the field

${ }^{b}$ this requires full knowledge of the cropping system characteristics and expertise on cropping systems

${ }^{\mathrm{c}}$ if soil erosion happens while a crop it is in the field, otherwise its effect has to be allocated 


\begin{tabular}{|c|c|c|c|c|c|}
\hline & Advantages & Disadvantages & App & $\operatorname{Com}^{b}$ & $\operatorname{Acc}^{c}$ \\
\hline $\begin{array}{l}\text { Allocation } \\
\text { approaches }\end{array}$ & $\begin{array}{l}\text { - They apply a clear } \\
\text { splitting among } \\
\text { different crops of } \\
\text { whole crop } \\
\text { rotation } \\
\text { - They maintain the } \\
\text { integrity of the } \\
\text { cropping systems } \\
\text { - They can be used } \\
\text { for agroforestry } \\
\text { and intercropping }\end{array}$ & $\begin{array}{l}\text { - Additional data } \\
\text { requirements (whole crop } \\
\text { rotation) } \\
\text { - Currently limited number } \\
\text { of compatible allocation } \\
\text { approaches available } \\
\text { - Lack of accuracy a } \\
\text { attribution for some } \\
\text { management interventions }\end{array}$ & $\mathrm{M}$ & $\mathrm{H}$ & $\mathrm{M}$ \\
\hline $\begin{array}{l}\text { Crop by } \\
\text { crop }\end{array}$ & -Easy to apply & $\begin{array}{l}\text { - It does not reflect } \\
\text { cropping systems } \\
\text { characteristics and LCA } \\
\text { related issues }\end{array}$ & $\mathrm{H}$ & $\mathrm{L}$ & $\mathrm{L}$ \\
\hline $\begin{array}{l}\text { Combined } \\
\text { approaches }\end{array}$ & $\begin{array}{l}\text { - They consider } \\
\text { temporal issues } \\
\text { related to cropping } \\
\text { systems } \\
\text { - They include the } \\
\text { effect of the } \\
\text { previous crop in } \\
\text { the field } \\
\text { - The cropping } \\
\text { systems issues are } \\
\text { accounted for if } \\
\text { they occur in the } \\
\text { short term (Crop } \\
\text { Sequence } \\
\text { approach) }\end{array}$ & $\begin{array}{l}\text { - more complex than other } \\
\text { approaches } \\
\text { - They do not account for } \\
\text { cropping system issues } \\
\text { occurring in the long term } \\
\text { (Crop Sequence approach) } \\
\text { - They attribute the impact } \\
\text { of the previous crops to } \\
\text { the current crops (Crop } \\
\text { Sequence approach) } \\
\text { - They cannot be applied for } \\
\text { intercropping and } \\
\text { agroforestry systems } \\
\text { - Only some aspects of the } \\
\text { cropping systems are } \\
\text { considered (i.e. } \\
\text { multioutput systems and } \\
\text { nutrients) (MiLA) }\end{array}$ & $\mathrm{M}$ & $\mathrm{H}$ & $\mathrm{H}$ \\
\hline
\end{tabular}

\footnotetext{
a Applicability

${ }^{\mathrm{b}}$ Comprehensiveness

${ }^{c}$ Accuracy
} 


\section{Figure captions}

Fig. 1 Schematic representation of the Cropping System approach to assess cropping systems characteristics within system LCA

Fig. 2 Schematic representation of methodological approaches to attribute cropping system characteristics to a crop in product LCA 
System LCA
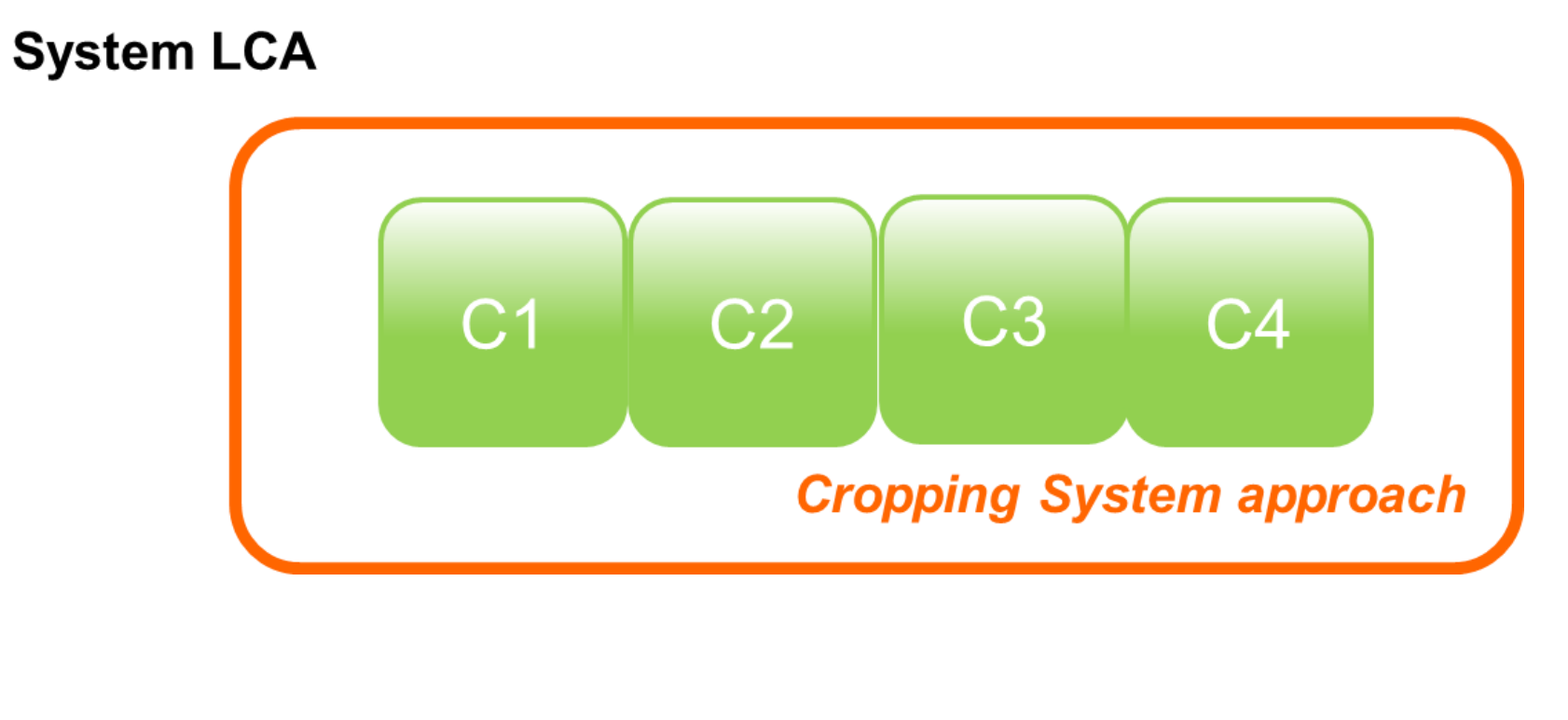

Figure 1

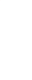

System LCA
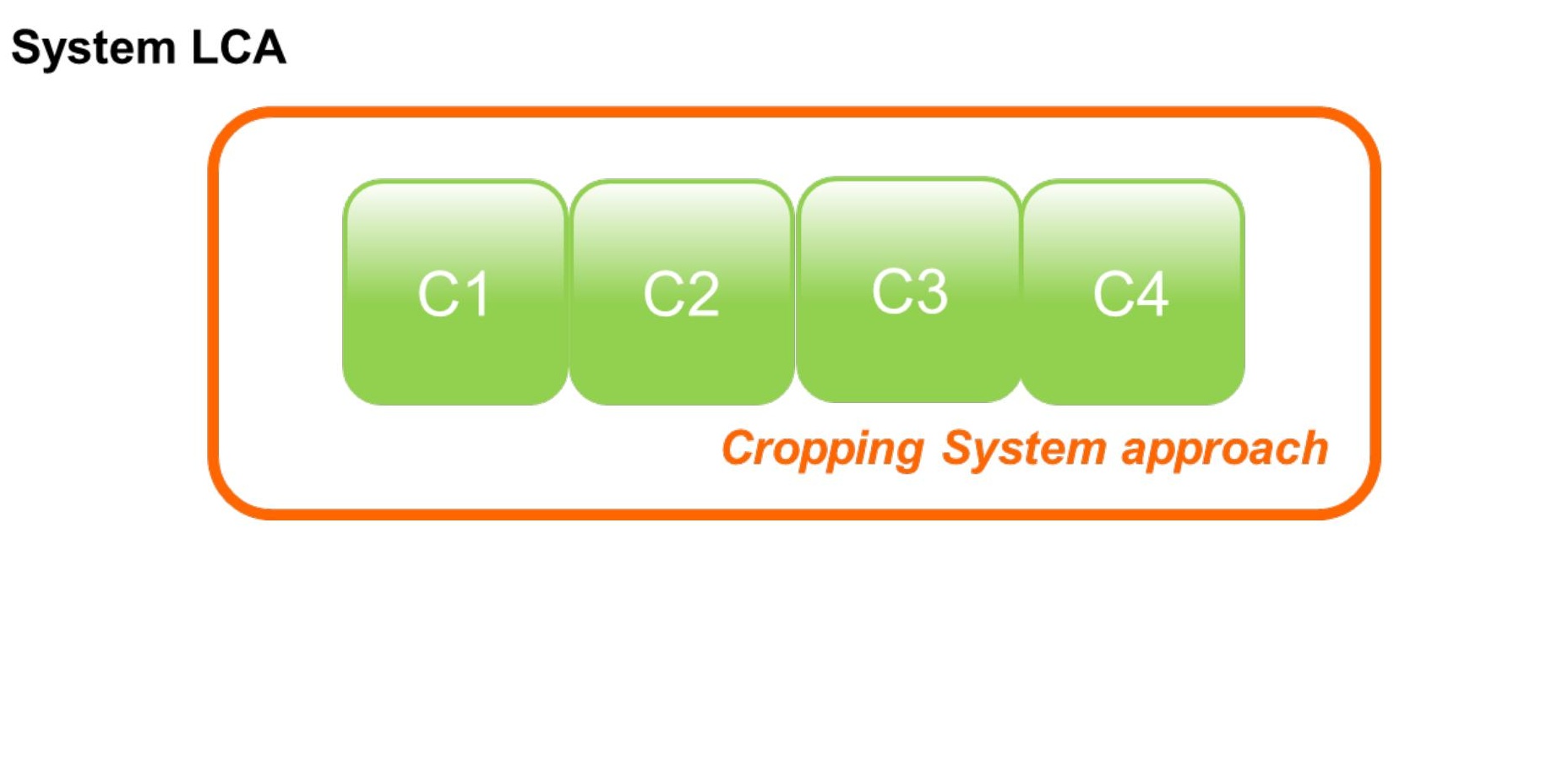
Interventions and outputs at level of entire rotation (allocated using generic criteria)

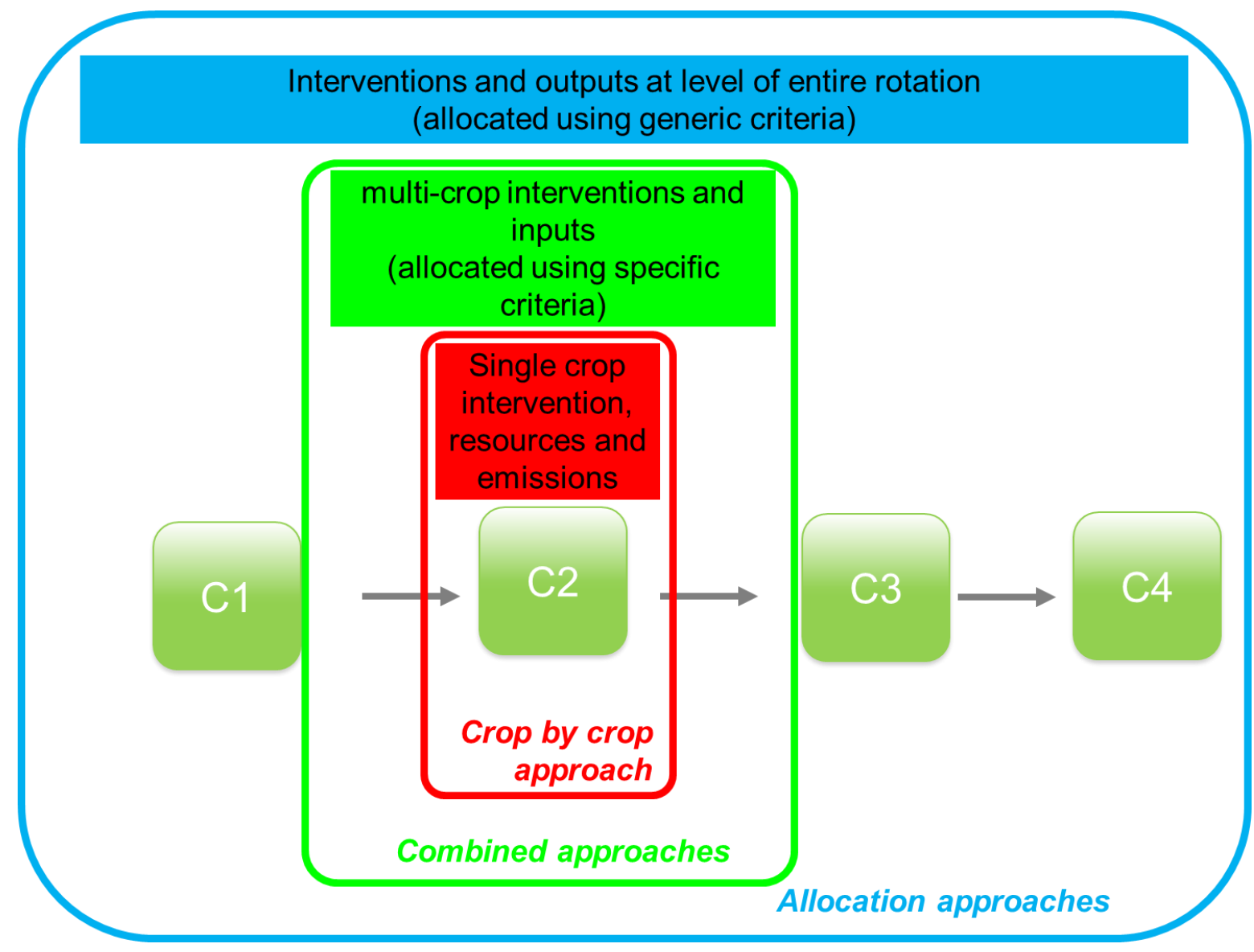

Figure 